\title{
Depressive Mood and Violent Behaviour among Teenagers: A Gender Dynamic Approach to the Study of Stressor Effects
}

\author{
Claire Gavray, Aurore Boulard
}

University of Liège, Liège, Belgium

Email: cgavray@uliege.be

How to cite this paper: Gavray, C., \& Boulard, A. (2021). Depressive Mood and Violent Behaviour among Teenagers: A Gender Dynamic Approach to the Study of Stressor Effects. Psychology, 12, 785-804.

https://doi.org/10.4236/psych.2021.125048

Received: January 29, 2021

Accepted: May 25, 2021

Published: May 28, 2021

Copyright $\odot 2021$ by author(s) and Scientific Research Publishing Inc. This work is licensed under the Creative Commons Attribution International License (CC BY 4.0).

http://creativecommons.org/licenses/by/4.0/

\begin{abstract}
Numerous studies have shown that the risk of depression in girls and the risk of violent behavior in boys progressively increase during adolescence. However, studies that clearly link the social mechanisms of gender to these results are relatively rare and studies that clearly delve into roots of these phenomena are even rarer still. The aim of this paper is to shed light on the genderization of spaces and life experiences during adolescence and its effect on adolescent mental and behavioral health. The recent scientific literature dedicated to this topic and the results of our own previous research have led us to define our hypotheses and analysis procedures. Concretely, we've tested the links between depression and violent behavior in both gender groups separately and we've investigated the potential role of gendered stressors and expectations influencing the developmental processes that lead to either depression or violent behaviour. The data used to perform our analysis of male and female pupils halfway through secondary education were drawn from the 2016 Belgian ISRD-3 study (International Study on SelfReported Delinquency, third wave) we have conducted. Our findings confirm that the stressors adolescents have to face and the significance they assign to them reflect the genderization of symbolic and material spheres (private and emotional for girls, public and competitive for boys). In terms of reaction to these stressors, depressive mood and violent attitude appear interlinked. Male gender norms appear to encourage boys to seek recognition through violent behaviors and to avoid emotional demonstrations. In this gender group, a high score of depression reflects sensitivity to stressors comparable to the female group but also, perhaps, a fear of rejection by peers. Nevertheless, these results must be considered with caution given the rapidly changing nature of the social world as well as the fact that the instru-
\end{abstract}


ments of measurement can themselves be governed by gender.

\section{Keywords}

Adolescence, Depressive Mood, Violent Behavior, Stressors, Gender Socialization

\section{Introduction}

\subsection{Aim of the Research}

This article presents the results of a study that focused on the impact of stressful events and developmental demands on depressive mood and violent behavior in male and in female adolescents. The gender approach brings added value in the field of development; it allows us to interrogate the social mechanisms of binarization and hierarchization between gender groups and what is considered masculine and feminine in a given society (Anthias, 2004; DiPrete \& Eirich, 2006).

Gender plays a role in the developmental process from early childhood onwards and constitutes a "culture" that is socially shared and affects all aspects of an individual's life: social roles, sexual expression, belief system, interests, and occupations, among others. This social mechanism can also influence physical and mental health. It affects the type of life experiences that young people encounter, the meanings they give to them, as well as their psycho-social and behavioral reactions to these. Following a general presentation of our data, we compare depression scores between girls and boys. Then, we describe how research has increasingly focused on examining gender roles, especially during adolescence. In particular, we pay close attention to how socialization and cognitive perspectives on gender have become closely related as they both emphasize the impact of the social environment on depression (Prinstein \& Aikins, 2004; Compian, Gowen, \& Hayward, 2009), violent behavior and victimization (Estévez, Povedano, Jiménez, \& Musitu, 2018). After that, we present our hypotheses and regression models. Our experimental method allowed us to examine the links between depression and violent behavior in both gender groups separately and investigate the potential role of gendered stressors and expectations influencing the developmental processes that lead to either depression or violent behaviour. It is worthwhile noting that Boulard and Leclercq (2020) argue that one should instead speak of depressive mood in such a context, while Glowacz and Born (2017) stress the importance of avoiding the over-dramatization violent behaviour by youths. Our article ends with a discussion of the results and their implications, both clinical and theoretical.

\subsection{Field Data}

Data from the 2016 Belgian ISRD-3 (International Study on Self-Reported De- 
linquency, third wave $)^{1}$ were used to identify a representative sample of male and female pupils in the middle of their secondary education. The ISRD dates back to the 1980s and was created by criminologists and psychologists eager to test the theories of their respective scientific discipline. This sample ${ }^{2}$ of 472 girls and 578 boys from secondary school (grade 9 and 10) is representative of all types of education and schools. The mean age of the participants was approximately 15 years old.

\section{Depressive Mood and Violent Behavior among Female and Male Teenagers}

\subsection{Descriptive Trends}

Community-based surveys provide estimations of depressive disorders among adolescents (Roberts, 2013). There is an overall consensus that female adolescents present higher rates of depression than adolescent males (Hankin, Mermelstein, \& Roesch, 2007; Boulard, Quertemont, Gauthier, \& Born, 2012) and this specificity appears at the beginning of adolescence. Hyde, Mezulis, \& Abramson (2008), for instance, found that a significant gender difference in rates of depression begins to emerge around age 13. Around this age, girls' rates of depression begin to increase while boys' rates remain fairly constant.

Our data confirmed significant differences in male and female rates of depression and violent behavior given that the variables we used to measure these rates were dependent on the questions asked in the ISRD-3 Belgian survey. A simplified scale of depressive mood was used in the ISRD-3 questionnaire on the basis of five items having saturated the Moos et al. (1985) depression scale ${ }^{3}$ responses the most in the previous ISRD-2 survey: feeling bad, depressed; feeling no self-confidence; having dark thoughts, thinking about unpleasant things; feeling loved by nobody; feeling worthless. The alpha value of the depression scale was .89 and there were significant differences between gender groups concerning the total scale ( $\mathrm{t}$ value $=8.11, \operatorname{Pr}>|\mathrm{t}|<.0001$ ). In accordance with the literature, girls had higher depression scores than boys on average. The mean score in the female subsample was 13.9 (sd 5.18). The one in the male group was 11.2 (sd 5.83). The least square means (standard deviation) were not strictly the same.

At the same time, as you can see in Table 1, the risk of severe/serious violent behavior increases among adolescent males. A scale of violent behavior was created corresponding to the number of different violent behaviors during the

${ }^{1}$ For a general presentation of the survey, see Enzmann, Kivivuori, Haen Marshall, Steneke, Hough and Killias (2018). The Belgian survey was conducted by L. Pauwels and N. Vettenburg (UGent) in Flanders and by C. Gavray (Uliege) in Wallonia.

${ }^{2}$ Following the instructions of the ISRD-3 methodology team, the survey took place in classes in two major cities and two medium-sized cities in Wallonia and Flanders. The sample is representative of the pupils in each of these cities. All children present in the classes ( $85 \%$ of the total list) were interviewed. Only 16 parents came forward to request that their child not participate in the survey. ${ }^{3}$ This scale of depression/negative well-being was developed by Moos since the 1970s, particularly in relation to the study of the impact of stressors and coping processes. This scale has been, for instance, validated by a lisrel analysis in Gavray \& Born (1995). It has been regularly used and updated to approach different age populations. 
Table 1. Percentages of boys and girls concerned by violent behaviors.

\begin{tabular}{|c|c|c|c|c|c|c|}
\hline \multirow[t]{2}{*}{ Type of offense } & \multicolumn{2}{|c|}{$\%$ boys concerned } & \multicolumn{2}{|c|}{$\%$ girls concerned } & \multicolumn{2}{|c|}{$\begin{array}{l}\text { Significance of the } \\
\text { difference between gender } \\
\text { groups }\end{array}$} \\
\hline & lifetime & last year & lifetime & last year & lifetime & last year \\
\hline graffiti & $13.2 \%$ & $10.2 \%$ & $8.3 \%$ & $6.9 \%$ & $\mathrm{P}=.01$ & NS \\
\hline vandalization & $14.2 \%$ & $11.5 \%$ & $10.1 \%$ & $8.3 \%$ & $\mathrm{P}=.002$ & NS \\
\hline extortion & $2.0 \%$ & $1.7 \%$ & $.7 \%$ & $.4 \%$ & $\mathrm{P}=.015$ & $\mathrm{P}=.04$ \\
\hline $\begin{array}{l}\text { possession of } \\
\text { a weapon }\end{array}$ & $20.6 \%$ & $16.5 \%$ & $8.0 \%$ & $5.3 \%$ & $\mathrm{P}<.0001$ & $\mathrm{P}<.0001$ \\
\hline Group fighting & $24.3 \%$ & $18.3 \%$ & $12.1 \%$ & $9.5 \%$ & $\mathrm{P}<.0001$ & $\mathrm{P}<.0001$ \\
\hline assault & $3.4 \%$ & $2.8 \%$ & $1.1 \%$ & $.8 \%$ & $\mathrm{P}=.004$ & $\mathrm{P}=.02$ \\
\hline animal abuse & $3.7 \%$ & $2.5 \%$ & $1.5 \%$ & $1.0 \%$ & $\mathrm{P}=.02$ & NS \\
\hline
\end{tabular}

previous 12 months. Each item (graffiti, vandalism, extortion, carrying a weapon (something that could be used to attack), group fighting, physically assaulting someone or an animal) was weighted according to its incidence in the sample. The alpha value of this score was .69. We were dependent on the set of questions used in international ISRD-3 questionnaire. The mean score in female subsample was .7 (sd 1.40). In male group, I was 1.33 (sd 1.99). The difference between boys and girls was significant $(t$ value $=-5.67, \operatorname{Pr}>|t|<.0001)$. In contrast with their results related to depression, female teenagers were less likely to have resorted to violent behavior and were less to have resorted to serious forms of violence.

\subsection{What Is Known about the Role of Stressors and Their Gendered Impact on Depression and Violent Behavior?}

These differences have often been interpreted through a naturalistic, biological lens, in connection with what is termed a "masculine" or "feminine essence". Nevertheless, a set of specific studies have focused on processes that might be involved in creating and maintaining such gender differences, especially in regards to depression (Martin \& Ruble, 2010). These studies have focused on the role of stressors and negative-life events.

Recent studies have shown that different types of stressors can have an impact on rates of depression as well as violent attitudes and behaviors. These same studies also highlight the central role played by an individual's perception of and feelings related to different events, as well as the stressors they face. During adolescence, a number of stressors can appear. Some concern sudden and unpredictable events, but others are related to repeated experiences. They may concern poor health, poor relations with their family, school or peers, body transformations.

Hankin and Abramson (2002) and Lewis et al. (2016) found that girls reported more depression than boys in response to stressors and they suggested that the 
early onset of puberty along with stressful life events could be the reason for an increased risk for depression in adolescent girls. However, Hamilton, Stange, Abramson and Alloy (2015) have argued that greater attention must be paid to the social and cultural roots of this trend. They are particularly interested in the role played by gender. Adolescence is undeniably a time of gender role intensification, particularly in Western cultures (Dehne \& Riedner, 2001), with increased gender role socialization and the stereotyping of girls as more interpersonally oriented. Many studies have shown, for instance, that negative body image associated with gender stereotypes-especially those related to attracting boys ( $\mathrm{Ru}$ dolph, 2009)—predicts increased depressive symptoms over time for adolescent girls (Stice \& Bearman, 2001; Compian, Gowen, \& Hayward, 2009). Stressful gender injunctions materialize concretely in physically and psychologically opposite characteristics. Traits associated with males-dominant, strong; competitive; independent; assertive; brave; and innovative-are linked to the public sphere. Traits associated with females, on the other hand-emotional; collaborative; nurturing; caring; attractive; but also humble; vulnerable; and dependent-are linked to the private sphere. Therefore, psychological reactions, such as depression, are often ascribed to the simple fact that girls are more emotional and more reactive to relationship disturbances in many studies (for instance, Rudolph, 2009).

Stressors may concern poor health, poor relations with their family, school or peers. Even if male and female adolescents experience the same stressors, Hankin et al. (2007) have shown that the meaning they assign to these differ and this, in turn, means they react differently to them as well.

\subsubsection{Family Stressors}

Identity development and increasing autonomy are seen as important stages in the adolescent life cycle (Kroger, 1996; Ryan, Alfeld-Liro, Fredricks, Hruda, \& Eccles, 1999; Steinberg, 2001). According to a study by Meadows, Brown and Elder (2006) that examined adolescent boys' and girls' exposure to negative life events, only some stressors account for the variance in depressive symptoms for adolescent girls. This is particularly evident in the case of family stressors, which are the most often associated to girls. For example, Crawford, Cohen, Midlarsky and Brook (2001) found that adolescent girls who had experienced family discord, such as divorce and parental distress, were at a greater risk for depression than adolescent boys. The link between parents' depressive symptoms and those of their offspring has also been observed in clinical and non-clinical samples (Moksnes, Moljord, Espnes, \& Byrne, 2010). While some researchers see girls as "naturally" more sensitive an emotional (Prinstein \& Aikins, 2004; Brody \& Hall, 2010), others argue that such attitudes are themselves a reflection of "gender order" (a concept popularized by Jill Matthews, 1984). As Blum, Mmari and Moreau (2017) point out, rates of depression increase at the same time as gendered expectations begin to wield more influence over individuals. Parents' expectations are more controlling and limiting for daughters and more emancipative for 
sons (Marks, Lam, \& McHale, 2009). According to Wichstrøm (1999), gender socialization exposes girls to higher rates of depression because it demands them to be more obedient and accountable for what happens to them. Hankin et al. (2007) have confirmed a link between depression in girls and the fact that females are taught from a young age to be more critical of themselves than males. In these studies, the gender hierarchy, especially in the family sphere, appears as a key determinant of the differences in mental health between girls/women and boys/men the world over (Das, Das, \& Das, 2012; Davar \& Ravindran, 2015; Stark, Cohen, Seff, \& Aldrich, 2020). Conversely, research has tended to neglect rates of violent behavior in the female group. But Cole, Nolen, Gircus and Paul (2006) noted that even if girls engage more often in passive coping strategies, such as rumination, rather than active strategies, the ones under the more strict surveillance and the less able to break free of gender roles can become aggressive. Social class appears as significant at this level only in the female group (Safford, Alloy, Abramson, \& Crossfield, 2007).

\subsubsection{School Stressors}

Teenage boys and girls do not have the same relation towards school and education. In the literature, girls are often described as more hardworking; they place more emphasis on receiving a good education and obtaining their diploma. They are also more easily depressed when they fail to meet teachers' and parents' schooling expectations. At the same time, girls suffer particularly from comparisons with other female classmates who enjoy more autonomy and freedom. On the other hand, male teenagers who appear too studious and show an interest in school risk their reputation because classmates associate these with weakness. Male adolescents are continually wary of teachers and demand justice and respect from them as well as other authority figures. Espelage and Swearer (2004) have shown that boys mainly see school as a space for self-presentation; they are also more confident about what the future holds no matter their results and are more prone than girls to rely on physical aggression if they become frustrated.

\subsubsection{Peer Group Stressors}

For a long time many studies have insisted on the fact that the period of adolescence is a challenging time, particularly with regards to building and maintaining one's reputation among peers, even if an individual's attachment to their parents provides a stable and secure base. During the transition to adolescence, the peer group is presented as a competitive source of attachment, and this especially the case among young people with no other secure attachments (Freeman \& Brown, 2001; Born, Cattelino, Gavray, \& Glowacz, 2015). If peers are presented as crucial for building autonomy and self-confidence in the public sphere, this has mainly been discussed for boys, and often with reference to the construction of their masculinity. David and Brannon (1976) already identified four key elements of traditional masculinity: 1) shunning of femininity; 2) the need to be powerful; 3) being self-sufficient; and 4) aggression/dominance. Connell and 
Messerschmitt (2005) have demonstrated how male adolescents are gradually taught to desire a high status, to defend male advantages and points of view in a broad social and political environment, and to exclude "weak" peers. Their behavior is policed by peers and this encourages them to adopt a "win at all costs" attitude and to engage in risk-taking behaviors (Kirby \& Kirby, 2017). At the same time, male endorsement of traditional masculinity norms predicts reduced help-seeking attitudes (Addis \& Mahalik, 2003), shame-proneness and a fear of emotions (MacBeth \& Gumley, 2012).

The challenge peers pose is not similar in both gender groups particularly because the sources of competition remain different. In the "gender order", each girl to be recognized as a respectable woman and, at the same time, as a sexual object $^{4}$ (Illouz, 1997, 2019). In short, the situations, stakes, and stressors male and female teenagers face, from a symbolic or material point of view, are not the same. Peer-related interactions are highly structured by gender and gender segregated peer groups have important influences on short- and long-term development (Zosuls, Miller, Ruble, Martin, \& Fabes, 2011).

\subsection{Violence versus Depression?}

Weaver, Borkowski, and Whitman (2008) found that, in general, lower levels of depression serve as risk factors for violent behavior from childhood onwards. Comparing the psycho-social development of boys and girls, Hankin, Mermelstein and Roesch (2007) and Hamilton, Stange, Abramson and Alloy (2015) have shown that feelings of personal victimization and of stress or unfairness at home or at school induce female teenagers to look inwards, which could lead to depression and even violent reactions in this group. The same effect was not found for boys.

Klostermann, Connell and Stormshak (2016) also found important differences between boys and girls during adolescence. Their results confirmed that early depressive symptoms were a higher risk factor for delinquent behavior in females than males and that females with severe conduct disorders were more likely to exhibit comorbid depression. On the basis of longitudinal comparisons, they demonstrated that, from the age of 13 onwards, the severity of depressive symptoms worsened substantially more for girls suffering from conduct disorders than for other groups of girls and for boys. Wiesner (2003) found bidirectional associations throughout adolescence for girls, with both delinquency predicting subsequent depression and depression predicting increases in subsequent delinquency. Concerning the manifestations of delinquency in both gender groups, international studies, such as the International Study on Self-Reported Delinquency, show that significant differences remain (Marshall, Neiss, \& Markina, 2019) and female adolescents often resort first to verbal violence or property offenses while male teenagers turn more quickly towards physical violence

(Vettenburg, Gavray, \& Born, 2010). That said, some girls exhibit serious forms

${ }^{4}$ Voices of Youth UNICEF, 2019 https://www.voicesofyouth.org/blog/masculinity-and-femininity. 
of violent behavior and adopt attitudes and values that mirror boys with the same profile. Some of them describe this evolution as a matter of survival, a duty to protect the weakest, or as a condition of acceptance in the boys' world. But the violent, assertive reactions presented by adolescent girls are judged negatively, unlike those of boys (Rudman, 1998).

Conversely, the research carried out up to now has mainly interpreted male violent behavior as an alternative to depression and as a way to assert dominance, (Kofler et al., 2011). Parent, Gobble and Rochlen (2019) talk of "toxic masculinity", which they link with lower levels of depression and anxiety. Nevertheless, since Gilbert' (1992) work, some researchers have also shown that some young men who do not feel recognized by dominant peers can find themselves at a disadvantage. This, in turn, can lead to submissiveness and the appearance of depressive symptoms. Recent studies are looking more closely at the notion of "male-based depression". They have shown that it is possible for men to be hostile, violent, aggressive, and bullying (Phillips, 2007) while also suffering from specific symptoms of depression associated with gender role stress, shame and anger (Cavanagh, Wilson, Kavanagh, \& Caputi, 2017; Feder, Levant, \& Dean, 2010), which are seldom investigated. An attention is also paid to the fact that untreated depression leads to suicide more often in men than women (Addis \& Hoffman, 2017).

\section{Procedure}

\subsection{Hypotheses}

As discussed above, the general aim of our statistical framework was to test the links between depression, violent behavior and a combination of stressors as influenced by gender expectations in both female and male teenagers' developmental processes. In view of previous research results and and in light of the traditional indicators that have influenced rates of depression and violent behaviour, we predicted depression and violent behaviour as two alternative paths within the male group, but not necessarily in the female group. As scientific literature confirms that gender socialization during adolescence leads to significant differences between female and male adolescents with regards to the type of stressor, we hypothesized that depression and violence would remain in strong relation to relational, family factors solely in the case of girls. Finally, we also thought it worthwhile to check the impact of social origin on rates of depression and violent behavior. This is because of the significant mutual social control boys are subject to and in contrast to the growing gap between girls who can protect themselves from the traditional stressors to which their sexual group is exposed and the less fortunate and "diplomatic" female adolescents.

\subsection{Presentation of the Stressors Tested in the Explanatory Models}

14 items referring to stressful events, stakes and demands related to the ISRD-3 
questionnaire were used as independent variables in regression models, with the same ones applied in each model (see Table 2). The literature has shown gender effects on these stressors, their subjective importance, and the reactions they provoke in the general adolescent population. They concern life spheres which are significant during adolescence (family, school, friends, openness in public and civic areas). This is not to suggest that the results would be achieved by testing items from other psychological or criminological theories. The aim here remains exploratory.

Table 2. Percentages of boys and girls concerned by potential stressors.

\begin{tabular}{|c|c|c|c|}
\hline stressors & $\mathrm{N}$ boys & $\mathrm{N}$ girls & $\begin{array}{c}\text { Significant } \\
\text { differences } \\
\text { between } \\
\text { B/G-P- }\end{array}$ \\
\hline Ever been injured by someone (assaulted, hit, etc.) & $4.7 \%$ & $3.7 \%$ & $>.005 \mathrm{NS}$ \\
\hline $\begin{array}{l}\text { Ever been threatened because of skin color, social or } \\
\text { national origin }\end{array}$ & $4.8 \%$ & $9.9 \%$ & .001 \\
\hline $\begin{array}{l}\text { Been hit, physically punished by his/her parent(s) } \\
\text { in the past } 12 \text { last months }\end{array}$ & $4.6 \%$ & $3.7 \%$ & $>.05 \mathrm{NS}$ \\
\hline $\begin{array}{l}\text { Ever been confronted with the death or the serious } \\
\text { illness of a parent }\end{array}$ & $4.4 \%$ & $9.0 \%$ & .003 \\
\hline $\begin{array}{l}\text { Ever been confronted with the excessive consumption of } \\
\text { alcohol and drugs by his/her parent(s) }\end{array}$ & $9.4 \%$ & $10.3 \%$ & $>.05 \mathrm{NS}$ \\
\hline $\begin{array}{l}\text { Ever been confronted with serious arguments } \\
\text { between his/her parents }\end{array}$ & $23.2 \%$ & $32.3 \%$ & .001 \\
\hline $\begin{array}{l}\text { Feeling of belonging to a deprived poor household (1) } \\
\text { pos. } 5-7 \text { (on a scale } 1-7 \text { ) }\end{array}$ & $9.3 \%$ & $14.5 \%$ & .01 \\
\hline Not attending general education (2) & $46.4 \%$ & $51.3 \%$ & .04 \\
\hline $\begin{array}{l}\text { Not feeling supported by teachers compared to } \\
\text { other classmates (1) pos. } 4 \text { - } 5 \text { (on a scale of } 5 \text { ) }\end{array}$ & $22.0 \%$ & $13.1 \%$ & .0006 \\
\hline $\begin{array}{l}\text { Often feeling that, when problems occur, they } \\
\text { automatically affect oneself (1) pos. } 4 \text { - } 5 \\
\text { (on a scale of 5) }\end{array}$ & $32 \%$ & $25 \%$ & .04 \\
\hline $\begin{array}{l}\text { Feeling that the police does not treat young people with } \\
\text { respect (1) pos. } 3 \text { - } 4 \text { (on a scale of } 4 \text { ) }\end{array}$ & $29 \%$ & $28 \%$ & $>.05 \mathrm{NS}$ \\
\hline $\begin{array}{l}\text { Feeling that school does not fulfil its emancipatory } \\
\text { mission or provide opportunities for equalization (1) } \\
\text { pos } 4 \text { - } 5 \text { (on a scale of 5) }\end{array}$ & $59 \%$ & $42 \%$ & $<.0001$ \\
\hline $\begin{array}{l}\text { Importance given to peers' recognition/admiration (1) } \\
\text { pos. } 5-6 \text { (on a scale of } 6)\end{array}$ & $53 \%$ & $42 \%$ & .01 \\
\hline $\begin{array}{l}\text { Not able to trust anyone in the neighborhood (1) } \\
\text { Pos. } 3 \text { - } 4 \text { (on a scale of } 4 \text { ) }\end{array}$ & $66 \%$ & $50 \%$ & $<.0001$ \\
\hline
\end{tabular}

(1) Note that, at the start of the analysis, these variables were continuous. We also ran the analyses with them. The results were nearly the same, but we thought it would easier to present the data and the results on the basis of binary items. (2) Note that, in the Belgian educational system, the type of educational institution attended (authorizing access to the university or not) deeply reflects social/cultural origin, which can considerably influence performance at school (Hindriks, Verschelde, Rayp, \& Schoors, 2010). Research has also shown that not attending general education can be interiorized as a sign of social relegation. 


\section{Results: Stressors Explaining the Degree of Violent Behavior and Depressive Mood by Gender Group}

\subsection{Stressors Linked with Violent Behavior}

To test the effect of these stressful life experiences and social demands, stepwise regressions (forward selection) were run with SAS in each gender group. One focused on "violence propensity" and the other on "depressive mood". After each step in which a new variable is added, all candidate variables in the model were checked to see if their significance had been reduced below the specified tolerance level.

Two initial stepwise regressions (SAS) were run to highlight the set of stressors linked with violent propensity (the 14 independent variables) by gender group.

Among girls $(\mathrm{N}=371)$, after 10 iterations, 7 variables emerged as significant concerning violent propensity, explaining $22 \%$ of the variance. The model is significant $(\mathrm{p}<0.0001)$.

In Table 3, violent behavior appears related to personal victimization and to concrete stressors connected to the parents and to the intimate sphere. There is also visible effect related to markers of household deprivation ("not attending general education" and "feeling of belonging to a deprived household").

Among boys (435), the stepwise regression revealed, after the 10th step, 4 variables which explained $16 \%$ of the variance. This model is also significant $(\mathrm{p}<$ $0.0001)$.

In Table 4, it is not the mark of personal/family victimization which emerges here but a broader feeling of non-recognition, injustice and discrimination from social institutions (school, police). The valorization by peers also appears to be very important.

\subsection{Stressors Linked with Depressive Mood}

The second set of regressions concerned the level of depressive mood by gender group. Running a new stepwise regression in each group, we added a new variable to the set of independent variables: the violent behavior score.

After 14 iterations, the stepwise regression performed in the female group explained $18 \%$ of the variance $(\mathrm{R}-$ Square $=.1805$ and $\mathrm{C}(\mathrm{p})=10.6079$; high significance of the model $\operatorname{Pr}>\mathrm{F}<.0001)$ and 8 variables stood out as significant.

In the female group, the results of Table 5 show traces of personal insecurity in the family sphere (income, disputes between parents once again), in the school sphere (personal feeling of not being supported effectively in school) and in the neighborhood (nobody to trust). New elements described as characteristic of male adolescents appear also, namely the criticism of institutions (school) and the importance of peer approval. We discover an effect of the level of violence committed.

We wanted to know if we could identify a similar relation between the violence score and depression in the male group as a significant correlation between 
Table 3. Significant variables significant in the model explaining violent propensity for girls.

\begin{tabular}{lccc}
\hline \multicolumn{1}{c}{ Variables } & Partial R & $\mathrm{F}$ & $p$ \\
\hline Not attending general education & .05 & 19.03 & $<.0001$ \\
Parent(s) with problems of alcohol/drug consumption & .04 & 16.45 & $<.0001$ \\
Ever been injured by someone & .03 & 12.37 & $<.001$ \\
Serious arguments between parents & .01 & 5.84 & $<.05$ \\
Ever been threatened because of skin color, social or & .01 & 5.25 & $<.05$ \\
national origin & & 4.68 & $<.05$ \\
Feeling of belonging to a deprived household & .01 & 4.95 & $<.05$ \\
Ever being hit, corrected by parent(s) & .01 & & \\
\hline
\end{tabular}

$\mathrm{N}=353$ subjects for which there were no missing data regarding the variables remained for analysis.

Table 4. Significant variables significant in the model explaining violent propensity for boys.

\begin{tabular}{lccc}
\hline \multicolumn{1}{c}{ Variables } & Partial R & F & $p$ \\
\hline $\begin{array}{l}\text { Feeling that the police does not treat young } \\
\text { people with respect }\end{array}$ & .05 & 22.15 & $<.0001$ \\
$\begin{array}{l}\text { Central importance given to peers' } \\
\text { recognition/ admiration }\end{array}$ & .04 & 17.44 & $<.0001$ \\
$\begin{array}{l}\text { Not in generaleducation } \\
\text { Feeling that school does not fulfil its } \\
\text { emancipatory mission or provide } \\
\text { opportunities for equalization }\end{array}$ & .02 & 7.62 & $<.01$ \\
\end{tabular}

$\mathrm{N}=394$ subjects for which there were no missing data regarding the variables remained for analysis.

Table 5. Significant variables in the model explaining the level of depressive mood in female group.

\begin{tabular}{lccc}
\hline \multicolumn{1}{c}{ Variables } & Partial R & F & $p$ \\
\hline Serious quarrels between parents & .050 & 20.75 & $<.0001$ \\
Not able to trust anyone in the neighborhood & .027 & 11.30 & .0009 \\
Not feeling supported by teachers & .023 & 10.09 & .0016 \\
High feeling of belonging to a deprived household & .026 & 9.02 & .0028 \\
Injured by someone (assaulted, hit) & .014 & 6.43 & .016 \\
Feeling that school does not fulfil its emancipatory & .012 & 5.42 & .020 \\
mission or provide opportunity for equalization & & & .016 \\
Score of violent behavior & .012 & 5.77 & .04 \\
Importance of peer recognition & .008 & 3.91 & \\
\hline
\end{tabular}

$\mathrm{N}=351$ subjects for which there were no missing data regarding the variables remained for analysis.

violence and depression scores existed in the female group: correlation of .14 in the female group ( $p=.0082)$ and of .6 in the male group and $p=.17$ ).

In the male group, the stepwise regression, also carried out over 14 iterations, explained $17 \%$ of the level of depressive mood $(\mathrm{R}$-Square $=.1701$ and $\mathrm{C}(\mathrm{p})=$ 
Table 6. Significant variables in the model explaining the level of depressive mood in male group.

\begin{tabular}{|c|c|c|c|}
\hline Variables & Partial $R^{2}$ & $\mathrm{~F}$ & $p$ \\
\hline Serious arguments between parents & .050 & 22.03 & $<.0001$ \\
\hline $\begin{array}{l}\text { Unable to trust anyone in the } \\
\text { neighborhood }\end{array}$ & .025 & 11.73 & .0007 \\
\hline Not attendinggeneraleducation & .017 & 7.94 & .0051 \\
\hline $\begin{array}{l}\text { High feeling of belonging to a deprived } \\
\text { household }\end{array}$ & .016 & 7.90 & .0052 \\
\hline Injured by someone (assaulted, hit) & .015 & 7.18 & .0076 \\
\hline Importance of peer recognition & .009 & 4.76 & .029 \\
\hline $\begin{array}{l}\text { Feeling that, when problems occur, they } \\
\text { automatically affect oneself }\end{array}$ & .008 & 4.18 & .041 \\
\hline $\begin{array}{l}\text { Not feeling supported by teachers } \\
\text { compared to other classmates }\end{array}$ & .007 & 3.82 & .048 \\
\hline
\end{tabular}

$\mathrm{N}=394$ subjects for which there were no missing data regarding the variables remained for analysis.

4015). 8 variables stood out as significant $(\operatorname{Pr}>\mathrm{F}<.0001)$.

In Table 6, we can see that the propensity for violence is not significant among the 8 elements contributing to an explanatory dynamic. As in the female group, this one reflects significant experiences and feelings of insecurity in family and close relationships. Two variables, however, do appear as significant when compared to girls: not attending general education and feeling that, when problems occur, they automatically affect oneself.

\section{Discussion}

As mentioned at the beginning of this article, only a handful of studies take into account the processes that might be involved in creating and maintaining the gender difference when it comes to depressive mood or violent behavior. Concerning the general sample we observed, it is important to emphasize that we do not see completely different realities and feelings between boys and girls but significant trends. Consequently, this casts doubt on arguments which posit that differences in rates of depression and violent behaviour between the sexes are biological in origin. Conversely, the influence of gender appears to be at work on several levels. This influence cannot only be found in relation to the risk of depressive mood or violent behavior, but it is also evident in their roots (stressful events and demands and how these are perceived).

Our three hypotheses were confirmed. The findings show first that the stressors adolescents have to face and the importance they give to them reflect the gender dualization of symbolic and material spheres (private and emotional for girls, public and competitive for boys). For instance, we can see in Table 2 that boys appear to be less attentive and sensitive to the problems in the family sphere and, even when they are, these family-related problems only have a visible impact on depression levels for this group. Life events leading to violent behaviors, 
on the other hand, appear to be linked to the performance of masculinity in public sphere (Table 4), while personal negative experiences (in family, school, neighborhood) explain depressive mood, it's visible in Table 6. If depressive symptoms gain the upper hand, the teenager deviates from the conventional path of his gender group. Depressive mood is accompanied by feelings that fate is inescapable and that they have fallen down the social hierarchy. This is similar to notion of marginalized masculinity in the typology proposed by Connell (2000). This explains our second result: depression and violent behaviour are two alternative paths, but only within the male group. In the scientific literature, gender injunctions serve to anesthetize and bury the depressive feelings of boys who encounter aggressive personal and family environments, but not of all of them. Through his typology of masculinities, Connell has shown that if boys appear weak psychologically, they are not considered as men. They are deemed inferior because they are associated with the feminine by their peers. In our results, we see them suffering from this social judgment perceived as an injustice (as seen from the significance of the type of education received and the feeling of being pursued by fate). At the same time, our results confirm that they suffer rates of depression similar to that of the girls' group, which result from stressful relational and family experiences.

In the female group, the explanatory variables of depressive mood as well as violent behavior appear significantly linked to feelings of non-recognition, personal insecurity and victimization within the family and school circle (Table 3 and Table 5). By the end of our regression analyses, only 1 of the 14 potential items did not have a significant impact on the explicative model: having experienced the death or serious illness of a parent. But at the same time, we note that throughout the developmental process, relationship fractures and stakes can be progressively exacerbated and extended in the private and public sphere. Societal evolution and, in particular, the gradual rapprochement of the ways of life and the projects of young women and young men can also explain this fact. Honneth (1992) has pointed out the shared and increasing importance of recognition $^{5}$ issues in our societies. For girls, one would assume that gender socialization largely continues to protect female teenagers from the most violent values, attitudes and behaviors. However, the greater the manifestations of violence, the greater the rates of depression. Future research could consider the hypothesis of bidirectionality between these two poles.

A third interesting result (visible in Table 3 ) shows that socio-economic background, and more precisely the awareness of this precariousness, plays a role on violent behavior only in the female group. This confirms previous scientific research on gender; boys "as a whole" tend to react by force. However, girls who come from the least socially advantaged families (which endorse gender-specific beliefs and attitudes) are faced with a higher risk of suffering of high negative life-events and of reacting to these with violence or depressive thoughts. In West-

${ }^{5}$ This term refers to the need of acceptance, consideration and respect in private and public relations (in couple and family, as worker and as citizen). 
ern societies, we can see a growing gap between the girls who have gained more independence and can protect themselves from traditional injunctions to which their sexual group is exposed and the less fortunate female adolescents who are less equipped to deal with such injunctions.

These results have an undeniable preventive and clinical implication. They require a deeper understanding of the gendered nature of the stressors individuals have to face during adolescence and the legitimacy of their reactions. Researchers and clinicians must be trained to take into account each individual context that models stressors and shapes responses to them. The psychologist have to take into account the variety of psycho-social logics, inter- and intragender groups, and the power structures that maintain them, knowing that these dynamics evolve over time, that historicity plays a role. Our results also show the need to question gender stereotypes more broadly, which includes not only interrogating the norms of femininity but also those of masculinity. Too often parents, professionals try to "save" girls, to empower them but fear to question masculine standards.

From a theoretical point of view, our findings reflect the four fundamental dimensions of gender highlighted by Bereni et al. (2020). Gender must not be exclusively be considered as intrinsic to identity. It is a social construct, a relational process of opposition between two poles which must be studied simultaneously (men and women, male and female characteristics). Gender signifies specific power relationships which are embedded in other power relationships, particularly in relation to social class, but it would be interesting to test other relationship dynamics.

If these results largely confirm our assumptions, they must also be considered in a nuanced manner. For instance, regarding the available data on which our results are based, designers of criminological or psychological international surveys have only given limited attention to items which allow for the in depth exploration of our hypotheses. Either the list of variables (often) unconsciously reflects characteristics linked to a particular group (boys in criminology boys and girls in psychology) or they are thought as "gender neutral" nowadays. The composition of both scales we used as dependent variables are likely concerned by these remarks. The Moos scale, in its abbreviated version, could explicitly take into account the symptoms described in the female group. Little attention has been paid to forms recently described as more masculine like shame and gender role stress (Smith, Mouzon, \& Elliott, 2018). Reviewing the Assumptions About Men's Mental Health: An Exploration of the Gender Binary. American journal of men's health, 12(1), 78-89.

The violent behaviors we investigated remain fairly standard and broadly associated with male delinquency. It would, for example, be worthwhile considering the development of online violence and (cyber)crime.

If regression analyses can identify significative trends for boys and girls, they do not account for intra-group variability and how it can evolve. Recently, some 
authors have called not only for a comparison of stressors that can affect depression in men and women but for a focus on intra-group differences (Smith, Mouzon and Elliott, 2018). A longitudinal approach would also provide interesting answers, such as whether, from a developmental point of view, it is only the temporalities of links between depression and violence that differ between boys and girls as observed by Wiesner (2003) It is important to acknowledge that research shows a peak of violent and delinquent behaviors in adolescence before a significant decrease in these, especially in the male group. Such an approach could also shed light on differences between general and clinical samples. All these questions and research perspectives are of the greatest interest both from a preventive and curative point of view. They would serve to undermine widespread belief in natural and immutable differences between the sexes and, at the same time, take into account the variety of objective and subjective experiences and reactions.

Lastly it would be important to consider how research results evolve over time and between generations as society's understanding of gender shifts. There is undoubtedly is an impact of the evolution of the context of thought as of the historical opportunities of the adolescents of both sexual groups. Indeed, we cannot deny that while gender socialization is perpetuated under old and new forms, our societies also promote diversity that, to some extent, liberate younger generations from certain forms of gendered belonging and injunctions. This is especially the case in neo-liberal and post-modern societies. Nevertheless, these evolutions have not yet managed to overturn the symbolic primacy of the "masculine" (Falquet, 2014).

There are several other research perspectives that may be useful in extending the field of gender studies. In a recent study on the same of population examined in this article ${ }^{6}$, cluster analysis revealed three groups of male adolescents identified by their relationship to stereotyping/discriminating gender values and attitudes. A first cluster of young people defends an "old-fashioned" social and family model that guarantees them a privileged status as a (future) man. This "traditional" model, however, appears to be giving way to two alternative models. The second cluster concerns young people of all origins who defend the theoretical principle of gender equality while at the same time justifying males' superior position in society and their greater opportunities in the economic, employment and decision-making spheres. The third model, which is mainly supported by young people from a relatively well-off socio-economic background, is open to the world and to its differences; it questions the need for competition and violence and emphasizes the importance of well-being and easy-living. It is, nevertheless, in this group that awareness concerning the inequalities between men and women is least acute. What could the links between these models and the object of our research here be? And similarly, what about the transformations of models of femininity?

${ }^{6}$ Article by Claire Gavray and Patrick Govers being finalized. 


\section{Conflicts of Interest}

The authors declare no conflicts of interest regarding the publication of this paper.

\section{References}

Addis, M. E., \& Hoffman, E. (2017). Men's Depression and Help-Seeking through the Lenses of Gender. In R. F. Levant, \& Y. J. Wong (Eds.), The Psychology of Men and Masculinities (pp. 171-196). Washington DC: American Psychological Association. https://doi.org/10.1037/0000023-007

Addis, M. E., \& Mahalik, J. R. (2003). Men, Masculinity, and the Contexts of Help. American Psychologist, 58, 5-14. https://doi.org/10.1037/0003-066X.58.1.5

Anthias, F. (2004). Social Stratification and Social Inequality: Models of Intersectionality and Identity. In F. Devine, M. Savage, J. Scott, \& R. Crompton (Eds.), Rethinking Class. Culture, Identities \& Lifestyle (pp. 24-45). London: Palgrave Macmillan. https://doi.org/10.1007/978-0-230-21454-5 2

Bereni, L., Chauvin, S., Jaunait, A., \& Ravillard, A. (2020). Introduction aux études sur le genre (3th ed.). Introduction to Gender Studies, Paris: De Boeck Supérieur.

Blum, R. W., Mmari, K., \& Moreau, C. (2017). It Begins at 10: How Gender Expectations Shape Early Adolescence around the World. Adolescent Health, 61, S3-S4. https://doi.org/10.1016/j.jadohealth.2017.07.009

Born, M., Cattelino, E., Gavray, C., \& Glowacz, F. (2015). Adolescent Delinquent Behaviours as Attempts of Group Social Integration and Well-Being through Social Acceptance? In R. Carneiro, \& M. A. Carneiro (Eds.), Youth, Offense and Well-Being. Can Science Enlighten Policy? (pp. 163-177). Lisbonne, Portugal: CEPCEP-Centro de Estudos dos Povos e Culturas de Expressao Portuguesa. Universidade Católica Portuguesa.

Boulard, A., \& Leclercq, C. (2020). Ado déprimé ou dépressif. Paris: De boeck Supérieur.

Boulard, A., Quertemont, E., Gauthier, J.-M., \& Born, M. (2012). Social Context in School: Its Relation to Adolescents' Depressive Mood. Journal of Adolescence, 35, 143-152. https://doi.org/10.1016/j.adolescence.2011.04.002

Brody, L. R., \& Hall, J. A. (2010). Gender, Emotion, and Socialization. In J. Chrisler, \& D. McCreary, D. (Eds.), Handbook of Gender Research in Psychology (pp. 429-454). New York: Springer., https://doi.org/10.1007/978-1-4419-1465-1 21

Cavanagh, A., Wilson, C. J., Kavanagh, D. J., \& Caputi, P. (2017). Differences in the Expression of Symptoms in Men versus Women with Depression: A Systematic Review and Meta-Analysis. Harvard Review of Psychiatry, 25, 29-38. https://doi.org/10.1097/HRP.0000000000000128

Cole, D. A., Nolen-Hoeksema, S., Girgus, J., \& Paul, G. (2006). Stress Exposure and Stress Generation in Child and Adolescent Depression: A Latent Trait-State-Error Approach to Longitudinal Analyses. Journal of Abnormal Psychology, 115, 40-51. https://doi.org/10.1037/0021-843X.115.1.40

Compian, L. J., Gowen, L. K., \& Hayward, C. (2009). The Interactive Effects of Puberty and Peer Victimization on Weight Concerns and Depression Symptoms among Early Adolescent Girls. The Journal of Early Adolescence, 29, 357-375. https://doi.org/10.1177/0272431608323656

Connell, R. W. (2000). The Men and the Boys. Berkeley, CA: University of California Press.

Connell, R. W., \& Messerschmidt, J. W. (2005). Hegemonic Masculinity: Rethinking the 
Concept. Gender \& Society, 19, 829-859. https://doi.org/10.1177/0891243205278639

Crawford, T. N., Cohen, P., Midlarsky, E., \& Brook, J. S. (2001). Internalizing Symptoms in Adolescents: Gender Differences in Vulnerability to Parental Distress and Discord. Journal of Research on Adolescence, 11, 95-118. https://doi.org/10.1111/1532-7795.00005

Das, J., Das, R. K., \& Das, V. (2012). The Mental Health Gender-Gap in Urban India: Patterns and Narratives. Social Science and Medicine, 75, 1660-1672. https://doi.org/10.1016/j.socscimed.2012.06.018

Davar, B., \& Ravindran, S. (2015). Gendering Mental Health: Knowledges, Identities and Institutions. New Delhi: Oxford University Press. https://doi.org/10.1093/acprof:oso/9780199453535.001.0001

David, D. S., \& Brannon, R. (Eds.) (1976). The Forty-Nine Percent Majority: The Male Sex Role. New York: Random House.

Dehne, K. L., \& Riedner, G. (2001). Adolescence, a Dynamic Concept. Reproductive Health Matters, 9, 11-15. https://doi.org/10.1016/S0968-8080(01)90003-5

DiPrete, T. A., \& Eirich, G. M. (2006). Cumulative Advantage as a Mechanism for Inequality: A Review of Theoretical and Empirical Developments. Annual Review of Sociology, 32, 271-297. https://doi.org/10.1146/annurev.soc.32.061604.123127

Enzmann, D., Kivivuori, J., Haen Marshall, M., Steneke, M., Hough, M., \& Killias, M. (2018). Introduction to the International Self-Report Delinquency Study (ISRD3). In D. Enzmann, J. Kivivuori, I. Haen Marshall, M. Steketee, M. Hough, \& M. Killias (Eds.), A Global Perspective on Young People as Offenders and Victims (pp. 1-6). Cham: Springer. https://doi.org/10.1007/978-3-319-63233-9 1

Espelage, D. L., \& Swearer, S. M. (Eds.) (2004). Bullying in American Schools: A SocialEcological Perspective on Prevention and Intervention. Mahwah, NJ: Lawrence Erlbaum Associates Publishers.

Estévez, E., Povedano, A., Jiménez, T. I., \& Musitu, G. (2018). Agression in Adolescence: A Gender Perspective? Psicothema, 30, 66-73.

Falquet, J. (2014). Ce que le genre fait à l'analyse de la mondialisation néolibérale [A Gender Perspective on Neoliberal Globalization: 'Global Women' in the Shadow of Military-Industrial Systems]. Regards Croisés sur l'Économie, 15, 341-355. https://doi.org/10.3917/rce.015.0341

Feder, J., Levant, R. F., \& Dean, J. (2010). Boys and Violence: A Gender-Informed Analysis. Psychology of Violence, 1, 3-12. https://doi.org/10.1037/2152-0828.1.S.3

Freeman, H., \& Brown, B. B. (2001). Primary Attachment to Parents and Peers during Adolescence: Differences by Attachment Style. Journal of Youth and Adolescence, 30, 653-674. https://doi.org/10.1023/A:1012200511045

Gavray, C., \& Born, M. (1995). Dynamiques des inégalités et fragilités sociales à la lumière du rapport entre emploi, famille et sécurité d'existence [Dynamics of Inequalities and Social Fragilities in the Light of the Relationship Between Employment, Family and Security of existence]. Bruxelles, Belgique: SSTC (Federal Services for Scientific, Technical and Cultural Affairs).

Gilbert, P. (1992). Counseling for Depression. London: Sage Publications.

Glowacz, F., \& Born, M. (2017). Psychologie de la délinquance [Psychology of Delinquency]. Paris: De Boeck Supérieur

Hamilton, J. L., Stange, J. P., Abramson, L. Y., \& Alloy, L. B. (2015). Stress and the Development of Cognitive Vulnerabilities to Depression Explain Sex Differences in Depressive Symptoms during Adolescence. Clinical Psychological Science, 3, 702-714. 


\section{https://doi.org/10.1177/2167702614545479}

Hankin, B. L., \& Abramson, L. Y. (2002). Measuring Cognitive Vulnerability to Depression in Adolescence: Reliability, Validity, and Gender Differences. Journal of Clinical Child Psychology, 31, 491-504. https://doi.org/10.1207/S15374424JCCP3104 8

Hankin, B. L., Mermelstein, R., \& Roesch, L. (2007). Sex Differences in Adolescent Depression: Stress Exposure and Reactivity Models. Child Development, 78, 279-295. https://doi.org/10.1111/j.1467-8624.2007.00997.x

Hindriks, J., Verschelde, M., Rayp, G., \& Schoors, K. (2010). School Tracking, Social Segregation and Educational Opportunity: Evidence from Belgium. Ghent: Ghent University, Faculty of Economics and Business Administration, 10/690.

Honneth, A. (1992). The Struggle for Recognition: The Moral Grammar of Social Conflicts. Cambridge, MA: MIT Press.

Hyde, J. S., Mezulis, A. H., \& Abramson, L. Y. (2008). The ABCs of Depression: Integrating Affective, Biological, and Cognitive Models to Explain the Emergence of the Gender Difference in Depression. Psychological Review, 115, 291-313.

https://doi.org/10.1037/0033-295X.115.2.291

Illouz, E. (1997). Consuming the Romantic Utopia: Love and the Cultural Contradictions of Capitalism. Berkeley, CA: University of California Press. https://doi.org/10.1525/9780520917996

Illouz, E. (2019). The End of Love: A Sociology of Negative Relations. Oxford: Oxford University Press.

Kirby, J. N., \& Kirby, P. G. (2017). An Evolutionary Model to Conceptualise Masculinity and Compassion in Male Teenagers: A Unifying Framework. Clinical Psychologist, 21, 74-89. https://doi.org/10.1111/cp.12129

Klostermann, S., Connell, A., \& Stormshak, B. (2016). Gender Differences in the Developmental Links between Conduct Problems and Depression across Early Adolescence. Journal of Research on Adolescence, 26, 76-89. https://doi.org/10.1111/jora.12170

Kofler, M. J., McCart, M. R., Zajac, K., Ruggiero, K. J., Saunders, B. E., \& Kilpatrick, D. G. (2011). Depression and Delinquency Covariation in an Accelerated Longitudinal Sample of Adolescents. Journal of Consulting and Clinical Psychology, 79, 458-469. https://doi.org/10.1037/a0024108

Kroger, J. (1996). The Balance between Self and Other (pp. 40-46). New York: Routledge.

Lewis, G., Jones, P. B., \& Goodyer, I. M. (2016). The ROOTS Study: a 10-Year Review of Findings on Adolescent Depression, and Recommendations for Future Longitudinal Research. Social Psychiatry and Psychiatric Epidemiology, 51, 161-170.

https://doi.org/10.1007/s00127-015-1150-y

MacBeth, A., \& Gumley, A. (2012). Exploring Compassion: A Meta-Analysis of the Association between Self-Compassion and Psychopathology. Clinical Psychology Review, 32, 545-552. https://doi.org/10.1016/j.cpr.2012.06.003

Marks, J. L., Lam, C. B., \& McHale, S. M. (2009). Family Patterns of Gender Role Attitudes. Journal of Research, 61, 221-234. https://doi.org/10.1007/s11199-009-9619-3

Marshall, I. H, Neissl, K., \& Markina, A. (2019). A Global View on Youth Crime and Victimization: Results From the International Self-Report Delinquency Study (ISRD3). Journal of Contemporary Criminal Justice, 35, 380-385. https://doi.org/10.1177/1043986219884814

Martin, C. L., \& Ruble, D. N. (2010). Patterns of Gender Development. Annual Review of Psychology, 61, 353-381. https://doi.org/10.1146/annurev.psych.093008.100511

Matthews, J. (1984). Good and Mad Women: The Historical Construction of Femininity 
in Twentieth Century. Sydney: George Allen \& Unwin.

Meadows, S. O., Brown, J. S., \& Elder, G. H. (2006). Depressive Symptoms, Stress, and Support: Gendered Trajectories from Adolescence to Young Adulthood. Journal of Youth and Adolescence, 35, 93-103. https://doi.org/10.1007/s10964-005-9021-6

Moksnes, U. K., Moljord, I. E. O., Espnes, G. A., \& Byrn, D. G. (2010). The Association between Stress and Emotional States in Adolescents: The Role of Gender and SelfEsteem. Personality and Individual Differences, 49, 430-435. https://doi.org/10.1016/j.paid.2010.04.012

Moos, R. H., Cronkite, R. C., Billings, A. G., \& Finney, J. W. (1985) Health and Daily Living Form Manuel (Revised Version). Standford: Veterans Administration and Stanford University Medical Centers.

Parent, M. C., Gobble, T. D., \& Rochlen, A. (2019). Social Media Behavior, Toxic Masculinity, and Depression. Psychology of Men \& Masculinities, 20, 277-287. https://doi.org/10.1037/men0000156

Phillips, D. A. (2007). Punking and Bullying: Strategies in Middle School, High School, and Beyond. Journal of Interpersonal Violence, 22, 158-178.

https://doi.org/10.1177/0886260506295341

Prinstein, M. J., \& Aikins J. W. (2004). Cognitive Moderators of the Longitudinal Association between Peer Rejection and Adolescent Depressive Symptoms. Abnormal Child Psychology, 32, 147-158. https://doi.org/10.1023/B:JACP.0000019767.55592.63

Roberts, J. (2013). Low Mood and Depression in Adolescence: Clinical Update. The British Journal of General Practice, 63, 273-274. https://doi.org/10.3399/bjgp13X667367

Rudman, L. A. (1998). Self-Promotion as a Risk Factor for Women: The Costs and Benefits of Counter Stereotypical Impression Management. Journal of Personality and Social Psychology, 74, 629-645. https://doi.org/10.1037/0022-3514.74.3.629

Rudolph, K. D. (2009). The Interpersonal Context of Adolescent Depression. In S. Nolen-Hoeksema, \& L. M. Hilt (Eds.), Handbook of Depression in Adolescent (pp. $377-$ 418). New York: Routledge, Taylor \& Francis.

Ryan, P. H., Alfeld-Liro, A. M., Fredricks, L. Z, Hruda, J. A., \& Eccles, J. S. (1999). Adolescents' Commitment to Developing Talent: The Role of Peers in Continuing Motivation for Sports and the Arts. Journal of Youth and Adolescence, 28, 741-763. https://doi.org/10.1023/A:1021643718575

Safford, S. M., Alloy, L. B., Abramson, L. Y., \& Crossfield, A. G. (2007). Negative Cognitive Style as a Predictor of Negative Life Events in Depression-Prone Individuals: A Test of the Stress Generation Hypothesis. Journal of Affect Disorders, 99, 147-154. https://doi.org/10.1016/j.jad.2006.09.003

Smith, D. T., Mouzon, D. M., \& Elliott, M. (2018). Reviewing the Assumptions about Men's Mental Health: An Exploration of the Gender Binary. American Journal of Men's Health, 12, 78-89. https://doi.org/10.1177/1557988316630953

Stark, L, Seff, I., Cohen, F., Aldrich, J., \& Allaf, C. (2020). Stressful Life Events and Their Unique Associations with Psychosocial Outcomes: A Gendered Analysis among High School Adolescents. Global Social Welfare. https://doi.org/10.1007/s40609-020-00179-Z

Steinberg, L. (2001). We Know Some Things: Adolescent-Parent Relationships in Retrospect and Prospect. Journal of Research on Adolescence, 11, 1-19. https://doi.org/10.1111/1532-7795.00001

Stice, E., \& Bearman, K. (2001). Body-Image and Eating Disturbances Prospectively Predict Increases in Depressive Symptoms in Adolescent Girls: A Growth Curve Analysis. Developmental Psychology, 37, 597-607. https://doi.org/10.1037/0012-1649.37.5.597 
Vettenburg, N., Gavray, C., \& Born, M. (2010). Belgium. In J. Junger-Tas, I. Haen Marshall, D. Enzmann, M. Killias, M. Steketee, \& B. Gruszczynska (Eds.), Juvenile Delinquency in Europe and Beyond. Results of the Second International Self-Report Delinquency Study (pp. 29-46). New York: Springer.

Weaver, C. M., Borkowski, J. G., \& Whitman, T. L. (2008). Violence Breeds Violence: Childhood Exposure and Adolescent Conduct Problems. Journal of Community Psychology, 36, 96-112. https://doi.org/10.1002/jcop.20219

Wichstrøm, L. (1999). The Emergence of Gender Difference in Depressed Mood during Adolescence: The Role of Intensified Gender Socialization. Developmental Psychology, 35, 232-245. https://doi.org/10.1037/0012-1649.35.1.232

Wiesner, M. (2003). A Longitudinal Latent Variable Analysis of Reciprocal Relations between Depressive Symptoms and Delinquency during Adolescence. Journal of Abnormal Psychology, 112, 633-645. https://doi.org/10.1037/0021-843X.112.4.633

Zosuls, K. M., Miller, C. F., Ruble, D. N., Martin, C. L., \& Fabes, R. A. (2011). Gender Development Research in Sex Roles: Historical Trends and Future Directions. Sex Roles, 64, 826-842. https://doi.org/10.1007/s11199-010-9902-3 